\title{
Cerebral Glucose Metabolism and Early EEG/aEEG in Term Newborn Infants with Hypoxic-Ischemic Encephalopathy
}

\author{
KRISTINA THORNGREN-JERNECK, LENA HELLSTRÖM-WESTAS, ERIK RYDING, AND \\ INGMAR ROSÉN \\ Department of Pediatrics [K.T.J., L.H.W.], Department of Clinical Neurophysiology [ER, IR], University \\ Hospital, SE-22185 Lund, Sweden
}

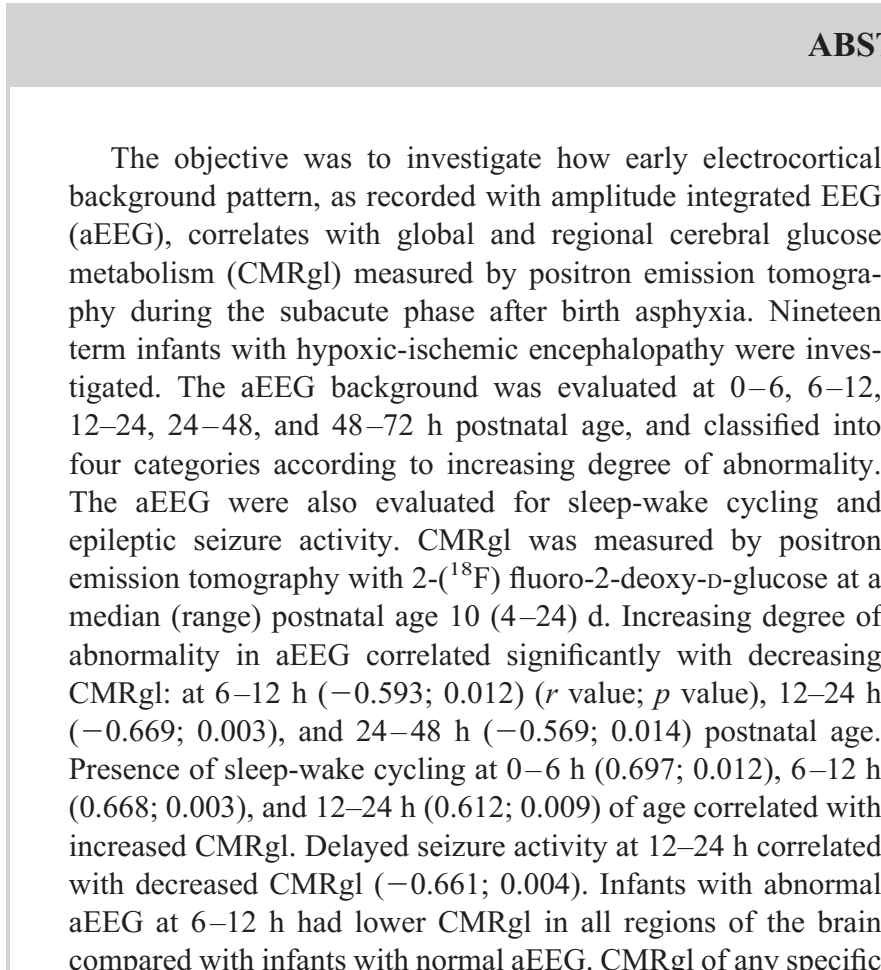

Birth asphyxia in term newborn infants remains a considerable problem in perinatal medicine, with high risk of mortality and disability (1-3). To predict outcome, the clinical neurologic assessment in grading HIE has proved to be of great value during the first days of life (4-6). We have recently shown that CMRgl is significantly lower in asphyxiated full-term infants who die or develop CP than in asphyxiated infants with no

Received March 20, 2002; accepted April 24, 2003.

Correspondence: Kristina Thorngren-Jerneck, M.D., Ph.D., Department of Pediatrics, University Hospital, Lund University, SE-221 85 Lund, Sweden; e-mail: kristina.thorngren-jerneck@pedi.lu.se

Supported by grants from the Swedish Medical Research Council (project nos. 4732, 0084), the Axel and Margaret Ax:son-Johnson Foundation, the Royal Physiographic Society, the First of May Flower Annual Foundation, the Linnéa and Josef Carlsson Foundation, the Sven Jerring Foundation, and The Medical Faculty of Lund University.

DOI: 10.1203/01.PDR.0000088068.82225.96 region of the brain was not significantly more correlated to aEEG than CMRgl of other regions. Early electrocortical background patterns, early presence of sleep-wake cycling, and delayed seizure activity were highly correlated with global CMRgl measured during the subacute phase after asphyxia, but did not correlate with any specific pattern of regional uptake. (Pediatr Res 54: 854-860, 2003)
aEEG, amplitude integrated EEG
BS, burst-suppression aEEG
CMRgl, cerebral metabolic rate of glucose
$\mathbf{C P}$, cerebral palsy
FDG, fluoro-deoxyglucose
HIE, hypoxic-ischemic encephalopathy
OM, orbito-meatal
PET, positron emission tomography
rCMRgl, regional cerebral metabolic rate of glucose
ROI, region of interest
SWC, sleep-wake cycling in aEEG
SZA, epileptic seizure activity in aEEG

signs of impairment at follow up (7). To select infants for early cerebroprotective treatment, which is a likely option in the near future (8), specific methods are required for very early identification of the infants who are at the highest risk of becoming disabled. aEEG has been used for very early prediction of outcome in full-term infants after birth asphyxia. There is a high risk for neurologic injury when the background aEEG is abnormal during the first hours of life $(9,10)$.

On postmortem examinations of newborn infants, it has been shown that the degree of EEG background abnormality reflects the number of damaged brain structures (11). In the adult human and in experimental research on adult animals, EEG activity correlated with both cerebral metabolic activity and cerebral blood flow $(12,13)$. Whether this correlation is present also in newborn infants has not previously been investigated, 
although one study on mechanically ventilated preterm infants showed that aEEG burst density during the first days of life correlated with CBF (14).

The aim of the present study was to investigate how very early electrocortical activity in full-term asphyxiated infants correlates with CMRgl, investigated somewhat later, in the subacute period, after secondary energy failure has passed and when more permanent damage has been established, and whether early aEEG background patterns correlate with specific regional uptake of CMRgl. These two methods have not previously been reported to have been applied together in the same infants.

\section{PATIENTS AND METHODS}

Subjects. Nineteen term infants with HIE after birth asphyxia were included in the study. The infants were born January 1995 to November 1999. They were inborn or referred to the Neonatal Intensive Care Unit at Lund University Hospital, a regional tertiary level unit. The following inclusion criteria were used: 1) term newborn (gestational age $>36 \mathrm{wk}$ ); and 2) birth asphyxia, defined as Apgar $<7$ at $5 \mathrm{~min}$, and at least one of the following criteria: a) severe umbilical cord acidosis $(\mathrm{pH}<7.10)$, b) late or prolonged decelerations on cardiotocography, or c)placental abruptio; 3) presence of HIE (4); 4) aEEG recorded during the first 48 postnatal hours; and 5) PET with quantification of total and rCMRgl. Clinical data are shown in Table 1.

The infants were neurologically examined daily during the first week of life and scored according to the maximum degree of HIE that developed (4). The infants had neurologic follow-up examinations at 4, 10, 18, and 24 mo of age. Assessment of outcome was made using items described by AmielTison (15). The children were classified as having disability, i.e. CP $(n=6)$ or epilepsy and visual impairment $(n=1)$, or no disability, i.e. without signs of cerebral injury at $2 \mathrm{y}$ of age. $\mathrm{CP}$ was classified according to the criteria of Hagberg et al. (3).

$\boldsymbol{a} \boldsymbol{E E} \boldsymbol{G}$. The aEEG records a single-channel EEG from a pair of biparietal electrodes (cerebral function monitor, CFM 4640 or Multitrace 2, Lectromed Devices Ltd., Letchworth, Hertfordshire, UK). The aEEG signal is amplified and passed through an asymmetric band-pass filter that strongly attenuates activity below $2 \mathrm{~Hz}$ and above $15 \mathrm{~Hz}$. After further processing, including semilogarithmic amplitude compression, rectifying, smoothing, and time-compression, the aEEG is continuously written out on paper, with a paper speed of $6 \mathrm{~cm} / \mathrm{h}(16)$. The aEEG is included in our clinical care procedures for asphyxiated infants together with at least one standard EEG examination. In the present study, the aEEG was recorded from median (range) 4.0 (1.4-44.5) postnatal hours, with 17 of 19 recordings initiated during the first $12 \mathrm{~h}$. Seventeen of the 19 infants had one to six (median, two) standard EEG recorded during the neonatal period. Standard EEG was not recorded in two infants with mild HIE who rapidly recovered.

Classification of aEEG and EEG. The aEEG recordings were analyzed by two independent interpreters without knowledge of the clinical or PET data (I.R., L.H.-W.). The interobserver agreement regarding the various features (see below) of the aEEG was close to $100 \%$. The aEEG at $6,12,24,48$, and 72 postnatal hours, as well as the intervals in between (i.e. $0-6,6-12,12-24,24-48$, and 48-72 postnatal hours, respectively) was classified regarding type of background pattern, presence or absence of SWC, and presence or absence of SZA (10).

Definition of aEEG background patterns was as follows:

1. Continuous normal voltage aEEG: continuous background activity, bandwidth $10-25 \mu \mathrm{V}(17,18)$ (Fig. 1A)

2. Continuous periodic aEEG: continuous background including periods with slightly discontinuous activity (lower bandwidth around $5 \mu \mathrm{V}$ ) (Fig. $1 B$ )

3. BS: bursts of high-voltage activity intermixed with flat periods (Fig. 1C, second part); or continuously extremely low voltage (LV), i.e. continuous background activity with maximum activity below 5-7 $\mu \mathrm{V}$ (Fig. 1D)

4. Inactive aEEG: flat tracing with electrocortical activity $<5 \mu \mathrm{V}$ (10) (Fig. 1E)

SWC was graded in three categories:

$2=$ Presence of SWC, i.e. a smooth cyclical variation (approximate frequency $0.5-1$ cycles/h) in maximum and minimum amplitudes. During quiet sleep, the more discontinuous background activity, corresponding to tracé alternant EEG, is seen in the aEEG as periods with increased bandwidth (18).

$1=$ Imminent SWC, i.e. some cyclical variation in the lower amplitude but not fully developed SWC.

$0=$ Absence of SWC.

Epileptic seizure activity. A transient abrupt rise in aEEG amplitude, usually followed by a distinct decrease in amplitude

Table 1. Clinical characteristics on 19 infants with HIE

\begin{tabular}{|c|c|c|c|c|}
\hline & $\begin{array}{l}\text { All infants } \\
(n=19)\end{array}$ & $\begin{array}{l}\text { Mild HIE } \\
(n=4)\end{array}$ & $\begin{array}{c}\text { Moderate HIE } \\
(n=12)\end{array}$ & $\begin{array}{l}\text { Severe HIE } \\
\quad(n=3)\end{array}$ \\
\hline GA at birth (wk) & $40(36-42)$ & $40.5(40-42)$ & $38.5(36-42)$ & $41(37-42)$ \\
\hline Birth weight (kg) & $3.5(2.2-5.0)$ & $3.5(3.5-3.8)$ & $3.4(2.2-4.1)$ & $4.2(2.9-5.0)$ \\
\hline Apgar (1 min) & $1(0-4)$ & $1.5(1-3)$ & $1(0-4)$ & $1(0-2)$ \\
\hline Apgar (5 min) & $4(1-6)$ & $4.5(3-6)$ & $4(1-6)$ & $3(2-3)$ \\
\hline Apgar (10 min) & $6(2-8)$ & $6.5(4-8)$ & $6(2-8)$ & $4(4-4)$ \\
\hline $\mathrm{pH}$ at birth & $6.94(6.68-7.25)$ & $7.05(6.68-7.25)$ & $6.94(6.7-7.18)$ & $6.85(6.81-7.04)$ \\
\hline $\mathrm{BE}$ at birth $(\mathrm{mmol} / \mathrm{L})$ & $-20.8(-27 ;-5)$ & $-21(-27 ;-5)$ & $-21(-27 ;-11)$ & $-21(-26 ;-16)$ \\
\hline Age at PET (d) & $10(4-24)$ & $11(4-12)$ & $9.5(5-24)$ & $11(10-11)$ \\
\hline GA at PET (wk) & $41(37-44)$ & $41.5(41-44)$ & $40(37-43)$ & $43(38-43)$ \\
\hline
\end{tabular}

Values are median (range). BE, base excess. 

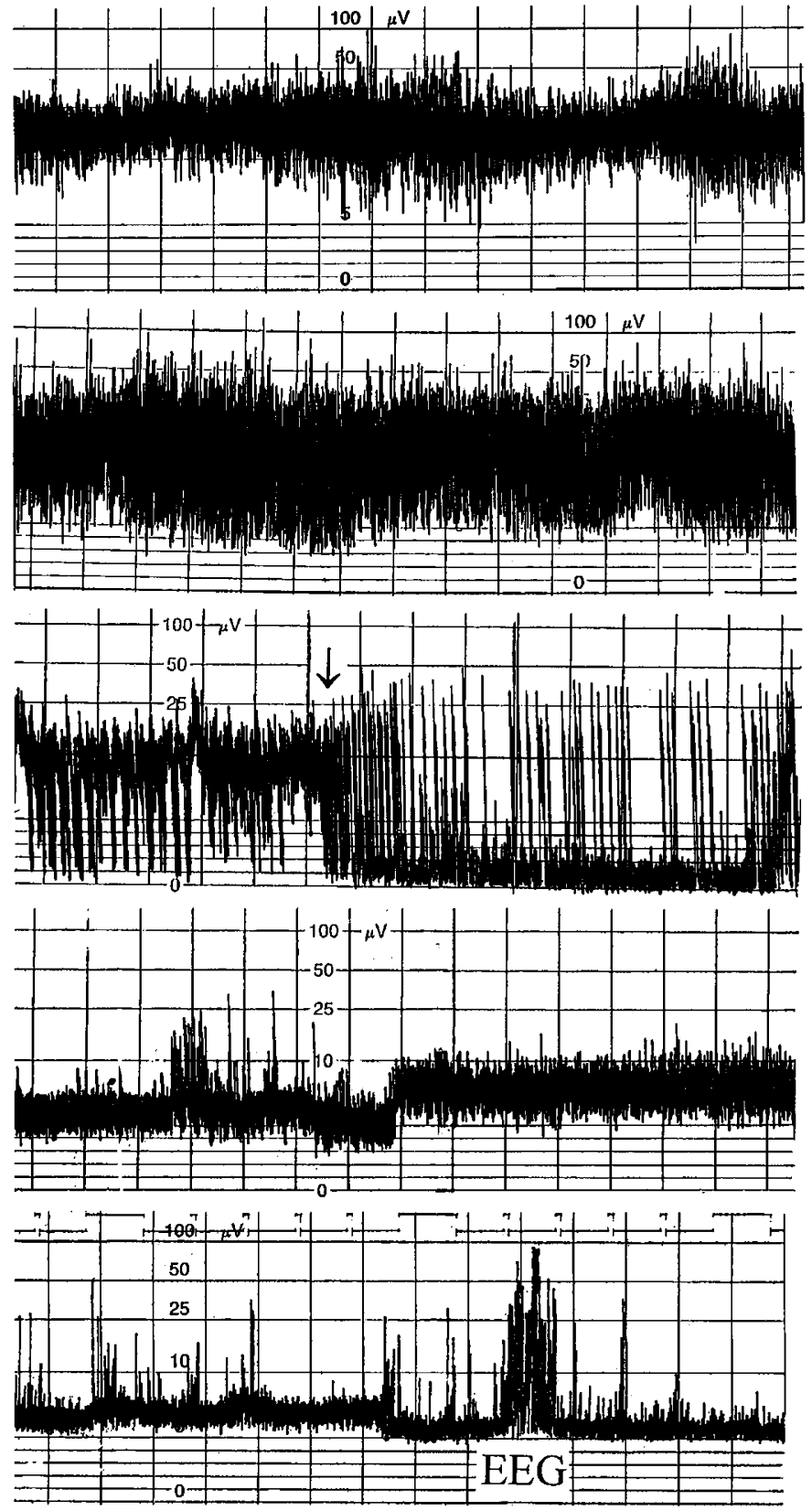

Figure 1. Background patterns of aEEG are defined as: $(A)$ Continuous normal voltage (CNV): Continuous background activity, (bandwidth 10-25 $\mu$ Volt) with sleep-wake cycling (SWC). (B) Continuous periodic (Cper): Continuous background including periods with moderately discontinuous activity (lower bandwidth around $5 \mu$ Volt), some variability but no clear SWC. (C) Initially a 'saw-tooth' pattern indicating status epilepticus, following antiepileptic treatment (arrow) change of background pattern to burst suppression (BS, i.e. bursts of high voltage activity intermixed with flat periods). (D) Continuously extremely low voltage (LV, continuous background activity with maximum activity below 5-7 $\mu$ Volt). (E) Inactive (IN, i.e. flat tracing with electro-cortical activity $<5$ Volt), confirmed by EEG (producing movement artefacts). Baseline shift presumably due to extracranial artefact.

that is not explained by external factors such as handling, repeated SZA resembles a "saw-tooth"; for an example, see the first part of the recording in Figure $1 C$. In the present study, SZA was defined as 1) single clinical seizures with corresponding aEEG changes; or 2) saw-tooth pattern with or without corresponding clinical seizures (19).
CMRgl was measured by PET and ${ }^{18}$ FDG. The PET measurements were performed using a Scanditronix PC 384-7 (Scanditronix Medical AB, Uppsala, Sweden), with a spatial resolution of $7 \mathrm{~mm}$. The investigations were performed at a postnatal age [median (range)] of 10 (4-24) d, corresponding to gestational ages $41(37-44)$ wk. At that time, the infants were clinically stable and no infant needed mechanical ventilation. All infants fasted for at least $2 \mathrm{~h}$ before the injection of ${ }^{18} \mathrm{FDG}$. One hour before scanning, 2-3.7 MBq/kg (54-100 $\mu \mathrm{Ci} / \mathrm{kg}){ }^{18} \mathrm{FDG}$ was injected intravenously. The infants were fed 30 min after the injection of ${ }^{18} \mathrm{FDG}$. The investigations were performed without any pharmacological sedation, although almost all infants were sleeping in the PET camera. The method for quantifying CMRgl, using the glucose metabolism of the erythrocytes, required only one blood sample (20). The PET investigation of the infants has earlier been described in greater detail (7).

\section{RCMRGL}

To quantify the regional distribution of CMRgl, each brain recording was rotated to a position corresponding to OM plane and sectioned into $100.5-\mathrm{cm}$ slices parallel to the OM plane. The rCMRgl was measured within three-dimensional ROI by a ROI-analysis computer program (Amersham Pharmacia Biotech, Uppsala, Sweden) by scaling the ROI set of each slice to the external limits of the brain slice. The position of ROI within each slice was based on an anatomic atlas (21). The analyzed regions were cerebellum; the Rolandic, prefrontal, temporal, parietal, and occipital cortical areas; the thalamus; and the basal ganglia. In a separate analysis, the regions perfused by the anterior, medial, and posterior cortical arteries were measured. The regional values were calculated in percentage of the mean total CMRgl for each infant. The rCMRgl was correlated with the aEEG background at $6-12 \mathrm{~h}$, the first time when the aEEG correlated significantly with global CMRgl (see "Results").

\section{RADIATION DOSIMETRY}

The absorbed dose was calculated according to the MIRD (medical internal radiation dose) models based on the distribution data of Gallagher et al. (22) assuming a 1-h bladder voiding interval. The bladder wall receives the highest absorbed dose, $0.8 \mathrm{mGy} / \mathrm{MBq}$. The estimated effective whole body dose equivalent was $0.16-0.17 \mathrm{mSv} / \mathrm{MBq}$.

\section{ETHICS}

The PET investigation was approved by the Research Ethics Committee, the Radiation Safety Committee at Lund University, and The Swedish Medical Products Agency. Informed consent for the PET scanning was obtained from all parents. Performance of aEEG was part of the clinical routine. 


\section{STATISTICS}

Nonparametric statistics were used. Spearman's test was used for correlation between global and regional absolute values of CMRgl and aEEG and outcome. Kendall's rank correlation was used to study the correlation between the relative regional CMRgl distribution and aEEG. Values are represented as median (range). A $p$ value $<0.05$ was regarded as significant.

\section{RESULTS}

Clinical outcome. Four infants developed mild HIE, 12 moderate HIE, and three developed severe HIE. Nine infants developed seizure patterns on aEEG during the first days of life: three before $12 \mathrm{~h}$, five at $12-24 \mathrm{~h}$, five at $24-48 \mathrm{~h}$, and three after $48 \mathrm{~h}$. All infants survived the neonatal period.

Six infants developed $\mathrm{CP}$, and two of them died, one at $8 \mathrm{mo}$ and one at $1.5 \mathrm{y}$ of age. One infant developed epilepsy and visual impairment without $\mathrm{CP}$, and 12 infants had no signs of impairment at 2 y follow-up.

CMRgl measured by FDG-PET. Global mean CMRgl decreased with increasing severity of $\mathrm{HIE}\left(\mathrm{r}_{\mathrm{s}}=0.61 ; p=0.006\right)$, and correlated significantly with later outcome $\left(\mathrm{r}_{\mathrm{s}}=0.48 ; p=\right.$ 0.038). The median (range) CMRgl in infants with mild HIE ( $n$ =4) was $43.5(37.7-51.0) \mu \mathrm{mol} / \mathrm{min} / 100 \mathrm{~g}$, in moderate HIE $(n=12) 22.4(13.0-52.1) \mu \mathrm{mol} / \mathrm{min} / 100 \mathrm{~g}$, and in severe HIE $(n=3) 15.0(10.2-27.6) \mu \mathrm{mol} / \mathrm{min} / 100 \mathrm{~g}$. CMRgl in the six infants who developed CP was $17.1(10.2-27.6) \mu \mathrm{mol} / \mathrm{min} / 100$ g. The 12 infants with no signs of impairment at $2 \mathrm{y}$ of age had CMRgl of $36.0(13.0-65.1) \mu \mathrm{mol} / \mathrm{min} / 100 \mathrm{~g}$. The infant who developed epilepsy and visual impairment but no CP had CMRgl $20.2 \mu \mathrm{mol} / \mathrm{min} / 100 \mathrm{~g}$. In 15 of the infants these results have been reported previously (7).

aEEG and outcome. The duration of the aEEG recordings ranged from 4.8 to $165 \mathrm{~h}$ (median, 54), with 17 of 19 recordings initiated during the first $12 \mathrm{~h}$. There was a significant correlation between aEEG background and outcome at all time intervals between 0 and $72 \mathrm{~h}$ postnatal age, as is shown in Table 2. No infant had an inactive (flat) tracing at $12 \mathrm{~h}$ postnatal age. One infant with severe HIE developed an inactive aEEG at $24-48 \mathrm{~h}$, had a CMRgl of $15.0 \mu \mathrm{mol} / \mathrm{min} / 100 \mathrm{~g}$, and later developed CP.

Correlation between aEEG and global CMRgl. Increasing degree of abnormality in aEEG background at $6-48 \mathrm{~h}$ correlated significantly with decreasing CMRgl. Table 3 shows the correlation between aEEG and global CMRgl during various time intervals. When analyzing the aEEG background pattern present at the end of each time interval, the correlation with CMRgl was also significant: $r(p)$ at $12 \mathrm{~h}$ : $-0.672(0.003)$; at $24 \mathrm{~h}:-0.675(0.003)$; and at $48 \mathrm{~h}$ postnatal age: -0.486 (0.041). Presence of SWC at all time intervals between 0 and $24 \mathrm{~h}$ postnatal age correlated significantly with increasing CMRgl (Table 3). Presence of SZA was associated with decreasing CMRgl at 12-24 $\mathrm{h}$ postnatal age, $r(p)-0.661$ (0.004). SZA before $12 \mathrm{~h}$ or after $24 \mathrm{~h}$ did not correlate with CMRgl (Table 3). Individual values of CMRgl in relation to the aEEG patterns at $6-12 \mathrm{~h}$ are shown in Figure 2.

Correlation between aEEG and rCMRgl. For correlation with rCMRgl, the time point $6-12 \mathrm{~h}$ for aEEG and SWC was chosen, the first time when there was a significant correlation between aEEG background and global CMRgl. The regional uptake of CMRgl was analyzed in two ways, absolute values and relative values (percentage of the global CMRgl in each infant). The absolute value of CMRgl in any chosen region of the brain was, like the global CMRgl, significantly correlated with aEEG and SWC but not with SZA. The rCMRgl values for the various aEEG categories at $6-12 \mathrm{~h}$ are given in Table 4. Figure 3 shows the $\mathrm{rCMRgl}$ in relation to SWC at 6-12 h.

When analyzing relative $\mathrm{rCMRgl}$ (percentage of global CM$\mathrm{Rgl}$ in each infant), there was no significant correlation between the various aEEG background patterns at $6-12 \mathrm{~h}$ and CMRgl of some specified regions of the brain. However the occipital region had a near significant correlation $(p=0.088$; $r=-0.353$ ) with the aEEG background. The relative CMRgl values for the three vascular territories did not significantly correlate with the aEEG background.

\section{DISCUSSION}

Several reports have previously shown that the aEEG contains accurate predictive information during the first hours of life after birth asphyxia $(9,10)$. A normal aEEG is predictive of good outcome, whereas an abnormal tracing predicts poor outcome. We have recently also shown that CMRgl is highly correlated with the degree of HIE and predictive of outcome (7). In the present study, we found a high correlation between the very early aEEG background pattern and global cerebral glucose metabolism, measured somewhat later, in the subacute phase after birth asphyxia. This is interesting, as these two techniques have not previously been reported to have been applied in the same children.

After asphyxia, the aEEG activity reflects the global electrocortical background activity, being largely independent of the position of the recording electrodes $(19,23)$. The very early

Table 2. Correlation between aEEG at various time intervals and outcome in 19 term infants with HIE after birth asphyxia; aEEG background (most abnormal category during time interval), presence of SWC, and SZA

\begin{tabular}{|c|c|c|c|c|c|c|c|c|c|c|}
\hline & \multicolumn{10}{|c|}{ Time (h postnatal age) } \\
\hline & \multicolumn{2}{|c|}{$0-6$} & \multicolumn{2}{|c|}{$6-12$} & \multicolumn{2}{|c|}{$12-24$} & \multicolumn{2}{|c|}{$24-48$} & \multicolumn{2}{|c|}{$48-72$} \\
\hline & $r_{\mathrm{s}}$ & $p$ & $r_{\mathrm{s}}$ & $p$ & $r_{\mathrm{s}}$ & $p$ & $r_{\mathrm{s}}$ & $p$ & $r_{\mathrm{s}}$ & $p$ \\
\hline aEEG background & 0.652 & $(0.008)$ & 0.845 & $(0.000)$ & 0.599 & $(0.011)$ & 0.504 & $(0.033)$ & 0.698 & $(0.017)$ \\
\hline SWC & & NS & 0.535 & $(0.027)$ & 0.605 & $(0.010)$ & 0.495 & $(0.037)$ & & NS \\
\hline SZA & & NS & & NS & & $(0.009)$ & & $(0.006)$ & & NS \\
\hline
\end{tabular}

Statistics performed by Spearman's rank-correlation test (aEEG and SWC), $r_{\mathrm{s}}(p)$, and chi-square analysis (SZA), respectively. 
Table 3. Correlation between aEEG at various time intervals and CMRg1, in 19 term infants with HIE after birth asphyxia; aEEG background (most abnormal category during time interval), presence of $S W C$, and $S Z A$

\begin{tabular}{|c|c|c|c|c|c|c|c|c|c|}
\hline & \multicolumn{9}{|c|}{ Time (h postnatal age) } \\
\hline & \multicolumn{2}{|c|}{$0-6$} & \multicolumn{2}{|c|}{$6-12$} & \multicolumn{2}{|c|}{$12-24$} & \multicolumn{2}{|c|}{$24-48$} & \multirow{2}{*}{$\frac{48-72}{p}$} \\
\hline & $r_{\mathrm{s}}$ & $p$ & $r_{\mathrm{s}}$ & $p$ & $r_{\mathrm{s}}$ & $p$ & $r_{\mathrm{s}}$ & $p$ & \\
\hline Worst aEEG & & NS & -0.593 & $(0.012)$ & -0.669 & $(0.003)$ & -0.569 & $(0.014)$ & NS \\
\hline SWC & 0.697 & $(0.012)$ & 0.668 & $(0.003)$ & 0.612 & $(0.009)$ & & NS & NS \\
\hline SZA & & NS & & NS & -0.661 & $(0.004)$ & & NS & NS \\
\hline
\end{tabular}

Statistics performed by Spearman's rank-correlation test, $r_{\mathrm{s}}(p)$.

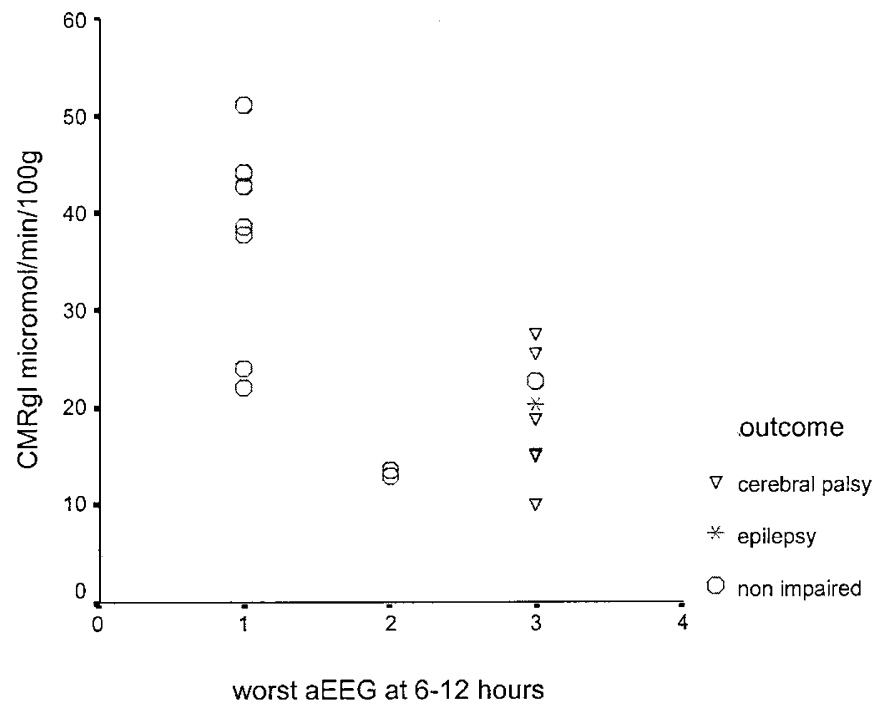

Figure 2. Scatter-plot of CMRgl values ( $\mu \mathrm{mol} / \mathrm{min} / 100 \mathrm{~g})$ in term infants with Hypoxic Ischemic Encephalopathy, at various aEEG patterns at 12 hours postnatal age (1. CNV, 2. Cper, 3. BS/LV). No infant had a flat tracing (IN) at this time point. Outcome of the infants is classified as non-impaired $\mathrm{O}$, epilepsy * and cerebral palsy $\triangle$. (In two non-impaired infants with CMRgl values 65 and $34 \mu \mathrm{mol} / \mathrm{min} / 100 \mathrm{~g}$, respectively, aEEG are missing at $12 \mathrm{~h}$ ).

aEEG reflects the activity from neurons affected by the hypoxia-ischemia, both surviving cells and those that are undergoing apoptosis (24). The FDG-PET examinations were performed in the subacute period at 8-12 d postnatal age, after the secondary energy failure has passed and the permanent cerebral damage has most likely been established (25). The CMRgl at this time reflects the glucose metabolism from neurons and glia cells that have survived, and it also reflects the decrease in the amount of neurotransmission in the synapses. The decreased CMRgl at this time consequently reflects the level of permanent cerebral damage.

The aEEG has been used, both clinically and experimentally, for investigating the cerebral recovery after birth asphyxia and experimental ischemia $(9,10,13,26-29)$. The background activity in the early aEEG is a good prognostic marker, which seems to be reliable despite possible blunting from loading doses of phenobarbitone (10). During and immediately after severe hypoxia-ischemia, the aEEG background is severely depressed before the electrocortical activity returns. When the aEEG activity returns it may do so in various ways, either as a quickly normalizing continuous background pattern or as an abnormal pattern, e.g. continuous but extremely LV or BS. A postmortem study in infants also suggested that different EEG background patterns could be associated with different types of brain injury (11). If such association could be found between early EEG background and specific brain injury after perinatal asphyxia, this could implicate earlier and more accurate prediction regarding the type of injury, and, perhaps also in the future, interventions that were specifically addressed for this type of injury.

Few studies have addressed the issue of whether early postasphyctic electrocortical background reflects specific patterns of brain injury. In postmortem investigations of newborn infants, Aso and colleagues (11) found widely distributed brain injury in infants with BS in the EEG. There was a direct correlation between the numbers of damaged structures and the degree of EEG abnormality. Electrocortical inactivity correlated with widespread injury in the cerebral cortex, striatum, thalamus, midbrain, and pons. This is consistent with experimental data showing that BS EEG corresponds with a disruption of corticothalamic circuits in adult cats (30). Also, in fetal sheep it has been shown that the electrophysiological background activity may have prognostic value and indicates the degree of cerebral injury. The duration of the EEG depression correlated well with the duration of ischemia and the degree of neuronal injury. Shorter duration of hypoxia-ischemia (10-20 min resulting in mild selective neuronal loss) gave a shorter duration of depressed EEG, whereas longer hypoxia-ischemia (30-40 min with laminar necrosis of cortex) gave a more prolonged depression of the EEG followed by epileptiform activity. The results indicated that after a severe hypoxicischemic insult, the parasagittal cortex becomes hyperexcitable before final loss of activity (31).

In adult rats exposed to various durations of cerebral ischemia, the time to recovery of the EEG activity correlated better with the duration of the ischemia than the $\mathrm{CBF}$ and cerebral metabolism did (13). It was suggested that neurophysiologic recovery in the postischemic period provides more accurate prognostic information than brain energy metabolism in indicating the extent of neuronal damage. In the present investigation, aEEG and CMRgl were both good for prognosticating outcome.

In a study of very preterm infants, there was also a correlation between burst rate in the aEEG background and cerebral blood flow as measured with 133-xenon (32). However, in newborn piglets suffering gradual arterial hypotension there was no correlation between EEG background activity, which was depressed also after the arterial hypotensive period, and neuronal oxygenation as measured with near-infrared spectroscopy and cytochrome aa3 (33). 
Table 4. Global and regional CMRgl values for the three aEEG background categories present at $6-12$ in 17 term infants with HIE

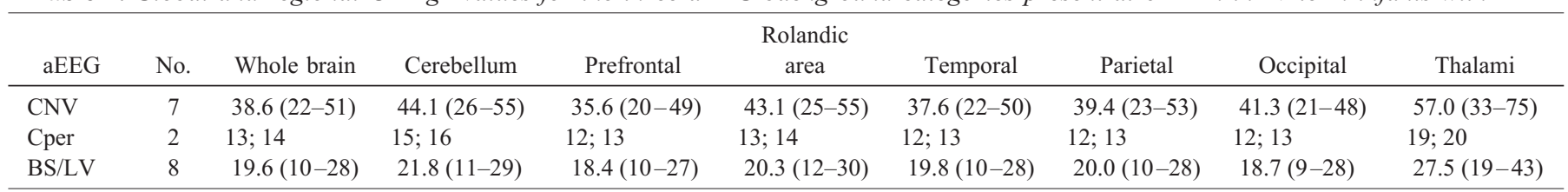

Values are median (range), $\mu \mathrm{mol} / \mathrm{min} / 100 \mathrm{~g}$. At this time point there was no infant with a flat aEEG. LV, continuously extremely low voltage.

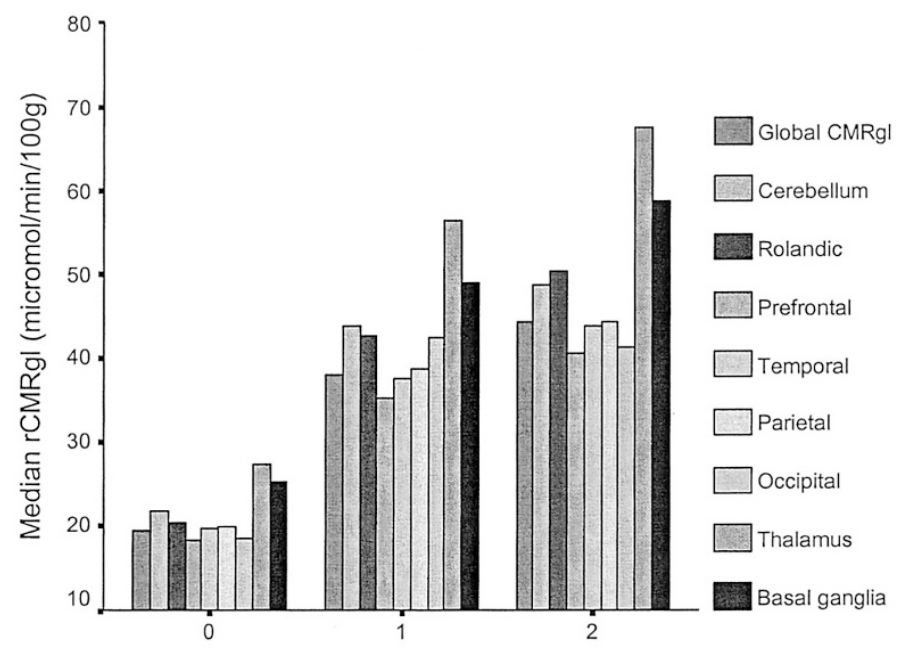

SWC at 6-12 h

Figure 3. Median values of rCMRgl in various regions of the brain in relation to sleep wake cycling (SWC), graded in three catogories: $2=$ presence of SWC, $1=$ imminent SWC, and $0=$ absence of SWC.

In the present study, early SWC was associated with good outcome. The "internal clock" for SWC is located in the brainstem (34), and presence of SWC indicates a normally functioning brainstem.

Previous studies of postasphyctic infants have shown various correlations between seizures and infant outcome $(6,35)$. The aEEG has been validated against the standard EEG, showing a good correlation regarding background patterns and epileptic seizure activity, but short, nonrepetitive seizures may be undetectable with the aEEG (19). In the present study, delayed SZA at $12-24 \mathrm{~h}$ correlated with low CMRgl values and worse outcome. Delayed seizures may be an indicator of secondary energy failure (25). In experimental studies on hypoxia-ischemia in fetal sheep, delayed seizures have shown good correlation with brain injury (36). A LV EEG seizure pattern is often present with parasagittal injury (31).

The CMRgl measurements were performed at a median age of $10 \mathrm{~d}$, when intensive care was finished and the infants were clinically stable. At this stage, the PET investigations could be performed without any sedation. The results could be obscured by sedation and drugs if PET is performed too early after the insult. However, in the present study, four of the 19 infants received phenobarbitone when the PET scan was performed. These four infants had moderate or severe HIE and they all developed CP. Their CMRgl were relatively low but not lower than the CMRgl for other infants with comparable HIE and outcome. We cannot exclude that phenobarbitone to these four infants may have affected their CMRgl, although it seems unlikely that any major changes in CMRgl occurred. This problem has been focused on in our previous work (7).

Abnormal signal intensity on MRI in the internal capsule has been shown to be a predictor of neurodevelopmental outcome after birth asphyxia (37). Recently, a study on neonates with acute neonatal encephalopathy showed good correlation between early EEG and MRI (38). A normal MRI was associated with normal EEG background activity and normal outcome; severe abnormalities on MRI correlated with marked EEG abnormalities and abnormal outcome. However, it was not investigated whether regional patterns on MRI corresponded with specific EEG patterns.

In conclusion, the present study has shown that early electrocortical background activity, aEEG, SWC, and delayed SZA (12-24 h) correlates with CMRgl measured during the subacute phase after asphyxia, reflecting the final degree of cerebral injury. Infants with abnormal aEEG at $6-12 \mathrm{~h}$ had lower CMRgl in all regions of the brain compared with infants with normal aEEG. However, CMRgl of any specific region of the brain was not significantly more correlated to the aEEG than CMRgl of other regions. Consequently, the aEEG did not correlate with any specific pattern of regional uptake of cerebral glucose.

Acknowledgments. The authors thank Sven-Erik Strand, Tomas Ohlsson, Anders Sandell, and Kjell Erlandsson for performing the PET scans.

\section{REFERENCES}

1. Volpe JJ 1994 Neurology of the Newborn, 3rd ed. WB Saunders, Philadelphia

2. Thorngren-Jerneck K, Herbst A 2001 Low 5-minute Apgar score: a population-based register study of 1 million term births. Obstet Gynecol 98:65-70

3. Hagberg B, Hagberg G, Beckung E, Uvebrant P 2001 Changing panorama of cerebral palsy in Sweden. VIII. Prevalence and origin in the birth year period 1991-94. Acta Paediatr 90:271-277

4. Sarnat HB, Sarnat MS 1976 Neonatal encephalopathy following fetal distress. A clinical and electroencephalographic study. Arch Neurol 33:696-705

5. Levene ML, Kornberg J, Williams TH 1985 The incidence and severity of postasphyxial encephalopathy in full- term infants. Early Hum Dev 11:21-26

6. Finer NN, Robertson CM, Richards RT, Pinnell LE, Peters KL 1981 Hypoxicischemic encephalopathy in term neonates: perinatal factors and outcome. J Pediatr 98:112-117

7. Thorngren-Jerneck K, Ohlsson T, Sandell A, Erlandsson K, Strand SE, Ryding E, Svenningsen NW 2001 Cerebral glucose metabolism measured by positron emission tomography in term newborn infants with hypoxic ischemic encephalopathy. Pediatr Res 49:495-501

8. Edwards AD, Wyatt JS, Thoresen M 1998 Treatment of hypoxic-ischaemic brain damage by moderate hypothermia. Arch Dis Child Fetal Neonatal Ed 78:F85-F88

9. Hellstrom-Westas L, Rosen I, Svenningsen NW 1995 Predictive value of early continuous amplitude integrated EEG recordings on outcome after severe birth asphyxia in full term infants. Arch Dis Child Fetal Neonatal Ed 72:F34-F38

10. Toet MC, Hellstrom-Westas L, Groenendaal F, Eken P, de Vries LS 1999 Amplitude integrated EEG 3 and 6 hours after birth in full term neonates with hypoxic-ischaemic encephalopathy. Arch Dis Child Fetal Neonatal Ed 81:F19-F23

11. Aso K, Scher MS, Barmada MA 1989 Neonatal electroencephalography and neuropathology. J Clin Neurophysiol 6:103-123

12. Ingvar DH, Sjolund B, Ardo A 1976 Correlation between dominant EEG frequency, cerebral oxygen uptake and blood flow. Electroencephalogr Clin Neurophysiol $41: 268-276$ 
13. Rosen I, Smith ML, Rehncrona S 1984 Quantitative EEG and evoked potentials after experimental brain ischemia in the rat; correlation with cerebral metabolism and blood flow. Prog Brain Res 62:175-183

14. Greisen G, Pryds O, Rosen I, Lou H 1988 Poor reversibility of EEG abnormality in hypotensive, preterm neonates. Acta Paediatr Scand 77:785-790

15. Amiel-Tison C 1978 A method for neurological evaluation within the first year of life: experience with full-term newborn infants with birth injury. Ciba Found Symp 59:107-137

16. Prior PF, Maynard DE, Sheaff PC, Simpson BR, Strunin L, Weaver EJ, Scott DF 1971 Monitoring cerebral function: clinical experience with new device for continuous recording of electrical activity of brain. BMJ 2:736-738

17. Verma UL, Archbald F, Tejani NA, Handwerker SM 1984 Cerebral function monitor in the neonate. I: Normal patterns. Dev Med Child Neurol 26:154-161

18. Thornberg E, Thiringer K 1990 Normal pattern of the cerebral function monitor trace in term and preterm neonates. Acta Paediatr Scand 79:20-25

19. Hellstrom-Westas L 1992 Comparison between tape-recorded and amplitudeintegrated EEG monitoring in sick newborn infants. Acta Paediatr 81:812-819

20. Sandell A, Ohlsson T, Erlandsson K, Strand SE 1998 An alternative method to normalize clinical FDG studies. J Nucl Med 39:552-555

21. Kretschmann HJ, Weirinich W 1986 Neuroanatomy and Cranial Computed Tomog raphy. Thieme Verlag, Stuttgart, pp 92-96

22. Gallagher BM, Ansari A, Atkins H, Casella V, Christman DR, Fowler JS, Ido T, MacGregor RR, Som P, Wan CN, Wolf AP, Kuhl DE, Reivich M 1977 Radiopharmaceuticals XXVII. 18F-labeled 2-deoxy-2-fluoro-d-glucose as a radiopharmaceutical for measuring regional myocardial glucose metabolism in vivo: tissue distribution and imaging studies in animals. J Nucl Med 18:990-996

23. Toet MC, van der Meij W, de Vries LS, Uiterwaal CS, van Huffelen KC 2002 Comparison between simultaneously recorded amplitude integrated electroencephalogram (cerebral function monitor) and standard electroencephalogram in neonates. Pediatrics 109:772-779

24. DeLorme AW, Mesce KA 1999 Programmed cell death of an identified motoneuron examined in vivo: electrophysiological and morphological correlates. J Neurobiol 39:307-322

25. Wyatt JS, Edwards AD, Azzopardi D, Reynolds EO 1989 Magnetic resonance and near infrared spectroscopy for investigation of perinatal hypoxic-ischaemic brain injury. Arch Dis Child 64(7 Spec No):953-963

26. Archbald F, Verma UL, Tejani NA, Handwerker SM 1984 Cerebral function monitor in the neonate. II: Birth asphyxia. Dev Med Child Neurol 26:162-168
27. Thornberg E, Ekstrom-Jodal B 1994 Cerebral function monitoring: a method of predicting outcome in term neonates after severe perinatal asphyxia. Acta Paediatr $83: 596-601$

28. Bunt JE, Gavilanes AW, Reulen JP, Blanco CE, Vles JS 1996 The influence of acute hypoxemia and hypovolemic hypotension of neuronal brain activity measured by the cerebral function monitor in newborn piglets. Neuropediatrics 27:260-264

29. al Naqeeb N, Edwards AD, Cowan FM, Azzopardi D 1999 Assessment of neonatal encephalopathy by amplitude-integrated electroencephalography. Pediatrics 103(6 Pt 1):1263-1271

30. Steriade M, Amzica F, Contreras D 1994 Cortical and thalamic cellular correlates of electroencephalographic burst-suppression. Electroencephalogr Clin Neurophysiol 90:1-16

31. Williams CE, Gunn AJ, Mallard C, Gluckman PD 1992 Outcome after ischemia in the developing sheep brain: an electroencephalographic and histological study. Ann Neurol 31:14-21

32. Greisen G, Pryds O 1989 Low CBF, discontinuous EEG activity, and periventricular brain injury in ill, preterm neonates. Brain Dev 11:164-168

33. Gavilanes AW, Vles JS, von Siebenthal K, Reulen JP, Nieman FH, van Sprundel R, Blanco CE 2001 Electrocortical brain activity, cerebral haemodynamics and oxygenation during progressive hypotension in newborn piglets. Clin Neurophysiol 112:52-59

34. Steriade M, Gloor P, Llinas RR, Lopes de Silva FH, Mesulam MM 1990 Report of IFCN Committee on Basic Mechanisms. Basic mechanisms of cerebral rhythmic activities. Electroencephalogr Clin Neurophysiol 76:481-508

35. Holmes GL, Lombroso CT 1993 Prognostic value of background patterns in the neonatal EEG. J Clin Neurophysiol 10:323-352

36. Williams CE, Gunn AJ, Synek B, Gluckman PD 1990 Delayed seizures occurring with hypoxic-ischemic encephalopathy in the fetal sheep. Pediatr Res 27:561-565

37. Rutherford MA, Pennock JM, Counsell SJ, Mercuri E, Cowan FM, Dubowitz LMS, Edwards AD 1998 Abnormal magnetic resonance signal in the internal capsule predicts poor neurodevelopmental outcome in infants with hypoxic-ischemic encephalopathy. Pediatrics 102(2 Pt 1):323-328

38. Biagioni E, Mercuri E, Rutherford M, Cowan F, Azzopardi D, Frisone MF, Cion G, Dubowitz L 2001 Combined use of electroencephalogram and magnetic resonance imaging in full-term neonates with acute encephalopathy. Pediatrics 107:461-468 